\title{
Risk-sharing in Rural Pakistan
}

\author{
SYEDA FIZZA GILLANI
}

\begin{abstract}
Risk-sharing is a fundamental form of economic behaviour. It can occur through formal insurance markets, informal family arrangements, community support, legal institutions (such as bankruptcy), or government tax-transfer programmes. Whatever the mechanism used to share risk, the extent of risk mitigation can greatly influence the welfare of all members of society. Understanding the degree of risk-pooling in society is important for policy-makers, since insufficient risk pooling may provide a basis for government intervention. Alternatively, if risks are being pooled adequately without the help of the government, government risk-sharing may be redundant.

This study explores the implications of the risk-sharing model, namely, that households which pool risks, either through formal markets or informal personal arrangements, experience correlated changes in their consumption through time. It conducts tests of within-village, across-village, within-district, and across-district risksharing using a new Pakistani panel data set—-the Pakistan Food Security Management Survey-collected by the International Food Policy Research Institute (IFPRI), Washington, D. C. Unlike studies for other Less Developed Countries (LDCs), these tests find very little or almost no evidence of risk-sharing among unrelated individuals within- and across-villages in the rural sector of Pakistan.
\end{abstract}

\section{INTRODUCTION}

Risk-sharing is a fundamental form of economic behaviour. It can occur through formal insurance markets, informal family arrangements, community support, legal institutions (such as bankruptcy), or government tax-transfer programmes. Whatever the mechanism used to share risk, the extent of risk mitigation can greatly influence the welfare of all members of society. Understanding the degree of risk-pooling in society is important for policy-makers, since insufficient risk-pooling may provide a basis for government intervention. Alternatively, if risks are being pooled adequately without the help of the government, government risksharing may be redundant. Islamabad.

Syeda Fizza Gillani is Research Economist at the Pakistan Institute of Development Economics,

Author's Note: This paper is based on my Ph. D. dissertation submitted to Boston University, USA. I am deeply indebted to my dissertation advisers, Professors Laurence J. Kotlikoff, Kevin Lang, and Jonathan Eaton, for their invaluable guidance. I am grateful to International Food Policy Research Institute (IFPRI), Washington, D. C., for providing me with the household-level panel data set. I would also like to thank Dr Harold Alderman, Dr Sohail J. Malik, and Professor Zvi Eckstein for their helpful comments on earlier drafts to this work. However, I alone bear the responsibility for any errors or omissions. 
As an example, take the issue of life-span uncertainty. As documented in Kotlikoff and Spivak (1981), individuals with a modest degrees of risk-aversion are willing to sacrifice significant fractions of their lifetime resources in order to gain access to actuarially fair life-span (annuity) insurance. If formal annuity markets are poorly developed, one might argue that the government should stimulate such markets by providing annuities through a social security system or similar institution. Before taking such steps, however, one should check whether communities are providing this form of insurance to their members. As Kotlikoff and Spivak demonstrate, significant risk-pooling does not necessarily require large numbers of risk-sharers. In the case of life-span risk, four or five community members can achieve the same level of the risk-pooling available with actuarially fair insurance.

Individuals have an incentive to trade and share risk due to two sources of heterogeneity, i.e., (1) differences in individual households' resources and (2) differences in individuals' preferences. Risk-sharing involves a distribution of resources across households so that the weighted marginal utilities across households are equalised. The major implication of the risk-sharing model is that if households are sharing risk in a given pool, then individual household consumption will not be affected by any shock to its own resources. In fact, changes in any household's consumption will depend on any shock to the collective resources of the risk-sharing pool. A sharing pool can be a few members of the same family, an extended family, a small village, a district or any other definition of a community. In the specific context of this study, only two definitions of the risk-sharing pool are being considered: the village and the district.

Consumption data can help identify the magnitude of uninsured risks [see Kotlikoff and Pakes (1988)] and clarify the membership of a common risk-pooling group. Controlling for measurement error, demographic change, and trend growth in consumption, deviations in household consumption from one period to the next will reflect the resolution of economic uncertainties. Uninsured negative (positive) resource shocks will be associated with reductions (increases) in consumption. Such consumption innovations will be correlated among all members of a risk-sharing pool: since risk-sharers pool shocks to their collective resources, all members of a risk-sharing pool will experience a common resource shock, which, in very special circumstances, might correspond to the average resource shock experienced by members of the risk pool.

The lack of panel data on consumption has limited economists to studying the magnitude of risks and the extent of risk-sharing. In the U.S., for example, the only long panel on consumption is provided by the Panel Study of Income Dynamics (PSID), and the consumption measured in the PSID consists only of food at home and food away from home. In the case of Less Developed Countries, the existence of panel data is very rare; one exception is the Pakistani Food Security Project's Panel 
data. The Pakistani Food Security Survey was conducted over three years, during which there were twelve interviews of each household. In each interview, a detailed set of information related to the consumption patterns of the household was collected. For the purpose of studying risk-sharing, this survey appears to be one of the best available for the LDCs.

This paper is divided into the following sections. Section II reviews the existing literature. Section III-a discusses the experimental design and derives the model for risk-sharing when the sharing pool is defined as a village. Section III-b discusses the implications of the risk-sharing model for the case when the risksharing pool is defined as one specific district. Section III-c discusses the econometric specifications of the model and points out various problems involved in estimations. This section also outlines the testable implications of the model. Section IV presents the empirical results; IV-a presents results of within-and across-village risk-sharing and IV-b presents results of within and across-districts risk-sharing. Section V concludes the study.

\section{REVIEW OF EXISTING LITERATURE}

This section surveys recent theoretical and empirical work on the implications of risk-sharing models. The focus of the survey is mainly on the tests based on consumption and income.

The implications of risk-sharing are emphasised in the early work by Wilson (1968). Micro consumption data has been used in several recent papers to test for altruism and/or risk-sharing. Andrew and Kotlikoff (1988) point out that altruism implies correlated consumption changes across cohorts. On balance, their tests, which use cohort data compiled from the on-going U.S. Consumer Expenditure Survey, reject altruism. Their results are also at odds with the prediction of perfect risk-sharing models.

Altonji, Hayashi, and Kotlikoff (1989) use the U.S. Panel Study of Income Dynamics (PSID) extended family data. This survey reports the consumption and incomes of parents and their adult children who are members of different households. Altonji et al. examine (1) the static implication of altruism that extended family members will share their initial level of resources, and (2) the dynamic implication of risk-sharing (whether altruistically motivated or not) that extended family members will share shocks to their resources. The data quite strongly reject such resource sharing; i.e., they reject both altruism and risk-sharing.

Other studies that examine risk-sharing using consumption data in the U.S. are Mace (1991) and Cochrane (1991). Mace and Cochrane use Consumer Expenditure Survey and the PSID, respectively, to test for perfect risk-sharing in the U.S. economy, which would imply correlated changes in consumption across different households. Mace uses two different specifications of the individual's utility 
function. She accepts the risk-sharing proposition for one of the specifications (exponential utility) while rejecting it for the other specification (power utility). Cochrane tests the proposition of full insurance by cross-sectional regressions of consumption growth on a variety of exogenous variables. He rejects full insurance for long illness and involuntary job loss, but not for spells of unemployment, loss of work due to strike, and an involuntary move.

Research on risk-sharing in LDCs using the new methodology has just begun. Townsend (1989) has examined consumption changes and risk-sharing in India. He uses indirect measures on the consumption of the households within three villages in India to test for risk-sharing. His consumption measure is derived by subtracting an estimate of saving from an estimate of income. While his consumption variable is clearly measured with error, he nonetheless finds that changes in the consumption of individual households within each of the three villages are highly correlated, even though income changes of villagers differ dramatically. Indeed, Townsend reports that controlling for average village consumption, the consumption of individual households does not, in general, depend on their own incomes. Given the significant measurement error in Townsend's data and the fact that he is considering only 40 households (albeit with 10 annual observations on each), one should not, perhaps, make too much of this single study; yet the results are intriguing. Townsend's finding of significant risk-sharing within villages in India appears to differ from Rosenzweig's (1988) findings (as discussed in the next section).

Paxon (1988) and Deaton (1989) also studied the response of LDCs households to income fluctuations. Their focus, however, is on the use of savings rather than risk-sharing arrangements to smooth consumption in the presence of income shocks.

Rashid (1990), using household consumption data from a survey of the year 1985-86 by the Government of Pakistan, analysed risk-sharing across farm households in different communities of Pakistan. She concludes that the individuals living in a community are able to insure completely against idiosyncratic shocks, but they are not able to smooth consumption across these communities. In her study, the measure of the community-wide shock is just the difference between the community's current and permanent income, where community's (permanent and current) income is just the individuals' (permanent and current) incomes added together. This measure of community-wide shock actually picks up community's fixed effects; hence it is another component of permanent income. In summary, though her study suffers from definitional and measurement problems, it is the first attempt to analyse risk-sharing behaviour in Pakistan.

The theoretical relationship between consumption, savings, income and risksharing has been discussed in the previous section. Literature gives us very mixed results of whether income risks are being pooled across the households (risk-sharing) 
or the households are smoothing their consumption over time using their savings and assets (consumption smoothing). To summarise, the evidence on risk-sharing, which is a first-order issue in economics, is unfortunately quite meagre, both for the DCs and LDCs.

\section{III-a TESTING WITHIN- AND ACROSS- VILLAGE RISK-SHARING}

As mentioned above, the changes in consumption over time of a household that pools risk with other households (whether for altruistic or selfish reasons) will depend on the collective resource shock of all households in the risk-sharing pool, rather than on the resource shock of the individual household. Thus, for households pooling risk there is a common factor determining changes in consumption over time. As described in Andrew and Kotlikoff (1987) and Altonji, Hayashi, and Kotlikoff (1989), this common factor is the change in the marginal utility of income. For estimation purposes, the change in the marginal utility of income can be treated as a fixed effect. If we control for this fixed effect as well as for demographics, the implication of within-village risk-sharing is that each household's consumption change will be uncorrelated with its change in resources which we proxy by the change in income.

To clarify these statements, consider the following specification for the utility of household $i$ in village $j$ at time $t$ :

$$
U_{i, j, t}=\sum_{a=0}^{D} P_{a, i, j, t} \theta_{a, i, j, t} \frac{C_{a, i, j, t}^{1-\gamma}}{(1-\gamma)} \quad \ldots \quad \ldots
$$

In (1) $U_{i, j, t}$ is the utility of the ith household in village $j$ at time $t, P_{a, i, j, t}$ is the number of members of the ith household who are age $a$ (where $a$ runs from zero to $D$, the maximum age in the household) at time $t, \theta_{a, i, j, t}$ is the weight attached by the household to the consumption of an age a member of the household at any point in time, and $C_{a, i, j, t}$ is the consumption of a member of the $i$ th household who is age $a$ at time $t$. The utility function in (1) is assumed to be isoelastic.

In Equation (1) household utility function is written as a function of the total consumption of all the members of the household at time $t$. Total consumption of the household is simply the sum of all members' consumption, i.e.,

$$
C_{i, j, t}=\sum_{a=0}^{D} P_{a, i, j, t} C_{a, i, j, t .} \quad \ldots \quad \ldots \quad \ldots \quad \ldots
$$

To find the optimal allocation of resources among the individual members of the households, maximise Equation (1) subject to (2). Substituting the demand 
function for the $C_{a, i, j, t}$ 's back into Equation (1), the utility function of the ith household in village $j$ at time $t$ can be written as an indirect function of $C_{i, j, t}$, viz.: ${ }^{1}$

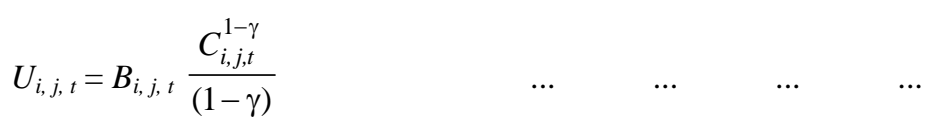

where:

$$
B_{i, j, t}=\left[\sum_{a=0}^{D} P_{a, i, j, t} \theta_{a, i, j, t}^{1 / \gamma}\right]^{\gamma}
$$

The expected intertemporal utility for the $i$ th household is the expectation of the sum of the household's intratemporal utilities weighted by a time preference factor. The summation runs from time $t$ to $\infty$. Thus,

$$
H_{i, j, t}=E_{t}\left[\sum_{s=t}^{\infty} U_{i, j, s}\left(\frac{1}{1+\rho}\right)^{s-t}\right] \quad \ldots \quad \ldots \quad \ldots
$$

where $E_{t}$ is the time $t$ expectation operator, $\rho$ is the rate of time preference, and $H_{i, j, t}$ is the expected utility of the ith household. Note that the demographics of the household enter through the $U_{i, j}$, s's. This specification encompasses the possibility that future demographics, i.e., the future values of the $\beta_{i, j}, t$ 's, are uncertain. Uncertainty with respect to demographics arises because of the life-span uncertainty of individual household members as well as the uncertainty with respect to the household's future fertility.

If the households within village $j$ are efficiently sharing risk, their risk-sharing behaviour can be described as the maximisation of a weighted sum of the values $H_{i, j, t}$ where the weights attached to each household $i$ 's expected intertemporal utility will reflect the initial resource distribution among the risk-pooling households as well as their relative bargaining abilities. Households with more initial resources or better bargaining abilities will, presumably, receive a higher weight, $\delta_{i, j}$ in the maximand given in (5).

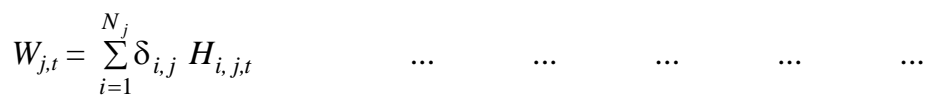

where $0<\delta<1$ and sum of $\delta$ is equal to $1 . N_{j}$ is the total number of households included in the risk pool. In considering this maximand, it is important to keep in mind that while the risk-sharing arrangements can be characterised as the solution to 
a planning problem, there is certainly no need to have a social planner effect the solution. The maximisation of (5) simply means that the risk-sharing arrangements made by the risk-sharers will be Pareto-efficient.

Total consumption by the risk pool in village $j$ at time $t, C_{j, t}$ equals the sum of the consumption of all households in the risk pool, thus:

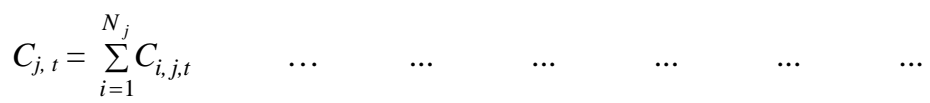

At any point in time the maximisation of (5), subject to the collective intertemporal budget constraint of the risk pool, must satisfy static first-order conditions. These static first-order conditions arise from maximising (5) subject to (6), taking $\mathrm{C}_{j, t}$ which is determined in the global optimisation, as given. These static first-order conditions ${ }^{2}$ can be expressed as:

$$
\delta_{i, j} \beta_{i, j, t} C_{i, j, t}^{-\gamma}=\delta_{k, j} \beta_{k, j, t} C_{k, j, t}^{-\gamma}=\lambda_{j, t} \quad \ldots \quad \ldots \quad \ldots
$$

where $\lambda_{j, t}$ is the shadow price of the Equation (6) constraint, $i$ and $k$ index two different households, and $j$ stands for the risk-sharing pool. This static first-order condition, which holds regardless of the type of uncertainty and budgetary constraints (including liquidity constraints) facing the risk-sharing pool, characterises the relative allocation of consumption between households $i$ and $k$ within village $j$. It is obvious that the division of the consumption between the households depends on the individual households' weight. In addition, since there is a single budget constraint in this problem, the weighted marginal utility of each household's consumption will be equated to the same shadow value of the budget constraint at each point in time. Hence, changes over time in the weighted value of each household's marginal utility will equal the changes over time in these shadow prices. Since the shadow prices $\left(\lambda_{t}\right)$ and their changes are not household-specific, the weighted ratio of changes in marginal utilities of consumption will be the same for each household.

To clarify this last point, consider Equation (7), but updated for time $t+1$ :

$$
\delta_{i, j} \beta_{i, j, t+1} C_{i, j, t+1}^{-\gamma}=\delta_{k, j} \beta_{k, j, t+1} C_{k, j, t+1}^{-\gamma}=\lambda_{j, t+1} \quad \ldots \quad \ldots
$$

For any ith household the ratio of (7) and (8) implies:

$$
\log \left(\frac{C_{i, j, t+1}}{C_{i, j, t}}\right)=-\frac{1}{\gamma} \log \left(\frac{\lambda_{j, t+1}}{\lambda_{j, t}}\right)+\frac{1}{\gamma} \log \left(\frac{\beta_{i, j, t+1}}{\beta_{i, j, t}}\right) \quad \ldots
$$

\footnotetext{
${ }^{2}$ For derivation of this result, see Appendix 2.
} 
and for any $k$ th household:

$$
\log \left(\frac{C_{k, j, t+1}}{C_{k, j, t}}\right)=-\frac{1}{\gamma} \log \left(\frac{\lambda_{j, t+1}}{\lambda_{j, t}}\right)+\frac{1}{\gamma} \log \left(\frac{\beta_{k, j, t+1}}{\beta_{k, j, t}}\right) \quad \ldots \quad \ldots
$$

A comparison of Equations (9) and (10) indicates that, controlling for changes in the household's demographic composition (the ratio of the $\beta$ 's), risk-pooling implies equal percentage changes in the consumption of each household in the risksharing pool. If households in village $j$ are sharing risk, this implies that, controlling for demographic change, all households in village $j$ should experience an equivalent percentage change in consumption from one period to the next, independent of the particular household's changes in income.

\section{III-b Risk-sharing within and across Districts}

The implications of the risk-sharing model are also tested by considering a broader definition of the risk-sharing pool, i.e., when the risk-sharing pool is defined to be a district rather than a village. Pakistan is divided into four provinces. One of the provinces was deleted from the sample after the fourth round because of some administrative problems. The rest of the sample consists of one district each from the N.W.F.P. and Sindh provinces and two districts (one rural and one urban) from the province of Punjab. All four districts in the sample have very distinct economic and social characteristics. All of them have different weather patterns, different soil types, different crop seasons, and hence different sources of incomes. Based on these facts, this study uses the model of risk-sharing to check the evidence of risk-sharing within and across districts as well as villages. In these regressions, the villages' fixed effects are replaced with district-level fixed effects and testing of the risk-sharing model has been continued as discussed earlier.

\section{III-c Econometric Specification}

Let $C_{m i, j, s}$ stand for measured consumption of household $i$, in village $j$, at time $s$. We assume that $C_{m i, j, s}=C_{i, j, s} \mu_{i, j, s}$ where $C_{m i, j, s}$ stands for measured consumption and $\mu_{i, j, s}$ is a measurement error. Using two first-order conditions for a given household for time $t$ and $t+1$, respectively, i.e., for time $t$

$$
\delta_{i, j} \beta_{i, j, t}\left(C_{m i, j, t} / \mu_{i, j, t}\right)^{-\gamma}=\lambda_{j, t} \quad \ldots \quad \ldots \quad \ldots \quad \ldots
$$

for time $t+1$

$$
\delta_{i, j} \beta_{i, j, t+1}\left(C_{m i, j, t+1} / \mu_{i, j, t+1}\right)^{-\gamma}=\lambda_{j, t+1} \quad \ldots \quad \ldots \quad \ldots \quad \ldots
$$


taking the log of both sides of the two equations

$$
\begin{aligned}
& \log \delta_{i, j}+\log \beta_{i, j, t}-\gamma \log C_{m i, j, t}+\gamma \log \mu_{i, j, t}=\log \lambda_{j, t} \quad \ldots \\
& \log \delta_{i, j}+\log \beta_{i, j, t+1}-\gamma \log C_{m i, j, t+1}+\gamma \log \mu_{i, j, t+1}=\log \lambda_{j, t+1} \quad \ldots
\end{aligned}
$$

subtracting (11)' from (12)' and re-arranging the terms, one gets

$$
\log \left(\frac{C_{m i, j, t+1}}{C_{m i, j, t}}\right)=-\frac{1}{\gamma} \log \left(\frac{\lambda_{j, t+1}}{\lambda_{j, t}}\right)+\frac{1}{\gamma} \log \left(\frac{\beta_{i, j, t+1}}{\beta_{i, j, t}}\right)+\log \left(\frac{\mu_{i, j, t+1}}{\mu_{i, j, t}}\right) \ldots
$$

As discussed earlier, the shadow prices $\lambda_{j, t}$ 's are not household-specific; they can be treated as fixed effects of the village and then dummy variables for each village can be used to capture these effects. Hence setting

$$
\mathrm{D}_{j, t+1}^{\prime} \tau=-\frac{1}{\gamma} \log \left(\frac{\lambda_{j, t+1}}{\lambda_{j, t}}\right)
$$

takes care of the village fixed effects. The term $D_{j, t+1}$ stands for a vector of time- and village-specific dummy variable, and $\tau$ is the corresponding vector of coefficients. In this specification, the village- and time-specific dummy variables control for the village- and time-specific dummy value of $\log \left(\lambda_{j, t+1} / \lambda_{j, t}\right)$. The change in the household demographics term (second term of the right-hand side of 13 ) is the vector of changes in household demographics. Let us define

$$
X_{i, j, t}^{\prime} \phi=\frac{1}{\gamma} \log \left(\frac{\beta_{i, j, t+1}}{\beta_{i, j, t}}\right)
$$

where $X_{i, j, t}^{\prime}$ is a vector of changes in household characteristics, and $\phi$ is a vector of corresponding coefficients. The examples of household characteristics are the number of different household members in different age-sex cells, the household head's age, education, and marital status, and the number of guests during the period $t$ as well as $t+1$. Substituting all of these components back into Equation (13), the econometric specification of the model becomes:

$$
\log \left(\frac{\mathrm{C}_{m i, j, t+1}}{\mathrm{C}_{m i, j, t}}\right)=X_{i, j, t}^{\prime} \phi+D_{j, t+1}^{\prime} \tau+\psi \log \left(\frac{Y_{i, j, t+1}}{Y_{i, j, t}}\right)+\epsilon_{i, j, t} \quad \ldots
$$

In (14) $Y_{i, j, t}$ stands for the current income of household $i$ in village $j$ at time $t$. The term $\log \left(Y_{i, j, t+1} / Y_{i, j, t}\right)$ is included to test the within-village risk-sharing hypothesis. Finally, $\in_{i, j, t}=\log \left(\mu_{i, j, t+1} / \mu_{i, j, t}\right)$ is the error term in the model. According to the 
within-village risk-sharing hypothesis, controlling for the common village resource shock, which is fully captured by $\log \left(\lambda_{j, t+1} / \lambda_{j, t}\right)$ (the $\left.D_{j, t+1}^{\prime}\right)$ vector in the regression), the change in income experienced by a particular household in the village should not be significant; i.e., under the null hypothesis $\psi=0$. Under the alternative hypothesis of no village risk-pooling, the village- and time-specific dummies will not control for household $i, j$, t's particular resource shock, and $\psi$ should be a significant positive coefficient, since some component of the change in the household's income between the two periods, presumably, will be unanticipated.

Equation (14) can be estimated in the cross-section. Alternatively, the data can be pooled over time by using a set of equations together to control for serial correlation in the $\in_{i, j, t}$ 's induced by the fact that the dependent variable in (14) for period $t$ and $t+1$ contains the common error term, $\log \left(\mu_{i, j, t+1} / \mu_{i, j, t}\right)$. However, this study uses only cross-section estimations, i.e., using only two years in each regression.

Notwithstanding Townsend's findings, the notion of perfect risk-sharing within the village strikes as implausible. Hence, it is expected to find a non-zero value of $\psi$. The interesting question may not be if the estimated value of $\psi$ is precisely zero, but if the value of $\psi$ is significantly different whether or not one controls for the village fixed effects. If controlling for the village fixed effect makes little difference to the estimated value of $\psi$, this would suggest essentially no risksharing among households within the village. If, on the other hand, the coefficient $\psi$ is substantially smaller as a result of controlling for the fixed effects, this would be indicative of substantial risk-sharing by the village.

In the case of risk-sharing across villages, it will also be interesting to determine whether the different components of the $\tau$ coefficient vector are significantly different. A finding of significant difference would rule out risk-sharing across villages, which Rosenzweig (1988) and Rosenzweig and Stark (1989) have stressed as quite important. Again, while it is likely to reject the equality of all the $\tau$ coefficients, and thus formally reject perfect across-village risk-sharing, if the variance in the $\tau$ coefficients is large compared to the variance of the dependent variable in (14), this would suggest quite different income shocks across villagesanother point stressed by Rosenzweig (1988) and Rosenzweig and Stark (1989)— combined with little or no risk-sharing across villages.

Income here is taken to be exogenous. If leisure enters the utility function, it may be inappropriate, depending on the precise form of the utility function to use income, inclusive of labour income, to test the model. Altonji, Hayashi, and Kotlikoff (1989) discuss the issue of variable labour supply at length and indicate how one can use lagged wage rates and assets in tests of risk-sharing if the labour supply is endogenous. Since the IFPRI data sets include wage rate and asset information, these 
can be used to test within-village risk-pooling. However, in this study, since the utility function does not include the leisure term, the income is taken as exogenous.

Another issue considered at length in Altonji et al. is the issue of the household utility function. Altonji et al. demonstrate that there is a very large class of utility functions delivering $\log \left(C_{i, j, t+1} / C_{i . j . t}\right)$ as the dependent variable in Equation (14). They and Browning, Deaton, and Irish (1985) also characterise the class of utility functions that delivers the first difference $\left(C_{i, j, t+1}-C_{i . j . t}\right)$ as the dependent variable in Equation (14). Equation (14) has been estimated both in logs and in levels. In the case of the level regressions change in income is used, rather than the proportional change in income, to test risk-sharing. Since consumption data is fairly detailed, Equation (14) is tested for sub-components of consumption as well as more aggregated measures of consumption.

This study uses a household level data set collected by the International Food Policy Research Institute (IFPRI), Washington, D. C. The IFPRI survey is a panel survey of the households in the rural sector of Pakistan. The data were collected from four districts in Pakistan. With the exception of the district of Faisalabad, the survey focused on households in Pakistan's poorest districts. ${ }^{3}$ As documented in Alderman and Garcia (1993), and Adams (1992), this data set is not a representative of rural Pakistan as a whole.

\section{EMPIRICAL FINDINGS AND RESULTS}

In empirical analysis, the income variable has been used as the sum of farm and non-farm wages, rental earnings and net crop profits, net returns to capital, and the zakat and pension received. ${ }^{4}$ Remittances or other transfers received are not included in income here, because some transfers may be responses to individual household's income shocks.

Empirically, for the test of within-village risk-sharing, I test the hypothesis

$$
\begin{aligned}
& H_{0}: \psi_{i}=0 \\
& H_{1}: \psi_{i} \neq 0
\end{aligned}
$$

Here $\psi_{i}$ are the coefficients of changes in income in the dynamic tests. For the testing of across-villages risk-sharing, the following null hypothesis is tested,

$$
\begin{aligned}
H_{0}: & \text { there is perfect risk-sharing across villages (i.e., all } \tau_{i} \text { 's are equal). } \\
H_{1}: & \text { there is no risk-sharing across villages (i.e., at least one of the } \tau_{i} \text { 's } \\
& \text { is not equal). }
\end{aligned}
$$

\footnotetext{
${ }^{3}$ For a detailed discussion on the sample selection and the data collection procedures, see Alderman and Garcia (1993). For variable definitions and summary statistics, see Gillani (1994).

${ }^{4}$ In the sample, total income is negative for some households. Since we are dealing with the log of the ratios, the households with negative as well as zero incomes are not included in the analysis.
} 
Here $\tau_{i}$ 's is the vector of coefficients related to village fixed effects and testing this hypothesis implies testing across villages.

\section{IV-a Results of Risk-sharing Within and Across Villages}

This section reports the empirical results obtained from fixed effect and nonfixed effect tests of the risk-sharing model. In this section, total income used is defined as in the previous section. The total consumption variable used is the total non-durable (current expenditures) consumption by the households. Total food consumption as well as all other current consumption by the household is included in the total consumption variable. For household demographics, the change in household size, the change in total number of meals taken outside the household by all household members, and the change in total number of visitors are included. Change in total consumption is regressed on the changes in own income and the changes in household demographics along with village fixed effects.

Empirical results reject the predictions of the risk-sharing model; namely, after controlling for village fixed effects, coefficients for the changes in own incomes should be zero. In estimation, most of these coefficients are significant and positive. The first two columns of Table 1 are the results from the fixed-effects model in the cases of log and levels regressions. Columns 3 and 4 present the results of the model without the village fixed effects in regressions. Most of the coefficients from both forms are significant and positive. The value of the coefficients is less in cases of without-fixed effects than in non-fixed effects results, but the difference is very small, i.e., controlling for the village fixed effects does not reduce the effect of the changes in income substantially. As discussed earlier, this rules out the possibility of risk-sharing within villages. The last column of Table 1 shows values of $F$ tests. ${ }^{5}$ These $F$ tests are included to test the hypothesis of across-villages risk-sharing. These $F$ tests reject the null hypothesis that the $\tau$ coefficients in the model are not significantly different from each other, i.e., the possibility of risk-sharing across villages in the sample is rejected. The last two rows of the table show the minimum, the maximum, and the mean value of the coefficients of the village fixed effects. The mean value of fixed effects is greater in the regression of years one and two than in the regressions of years two and three.

$$
\begin{aligned}
& { }^{5} F \text { tests in this case is defined as } \\
& F(J, T-K-J)=\frac{\left(S S E_{R}-S S E_{U}\right) / J}{S S E_{U} /(T-K-J)}
\end{aligned}
$$

where $S S E_{R}$ is the residual sum of squares from the model without fixed effects, $S S E_{U}$ is the residual sum of squares from the model with fixed effects, $J$ is the total number of fixed effects (we have a total of 44 villages in our sample, so $J$ in this case in (43) included in the model, $T$ is the total number of observations, and $K$ is the number of parameters estimated, excluding fixed effects. 
Table 1

Risk-sharing Within- and Across-villages

Total Expenditures and Total Income

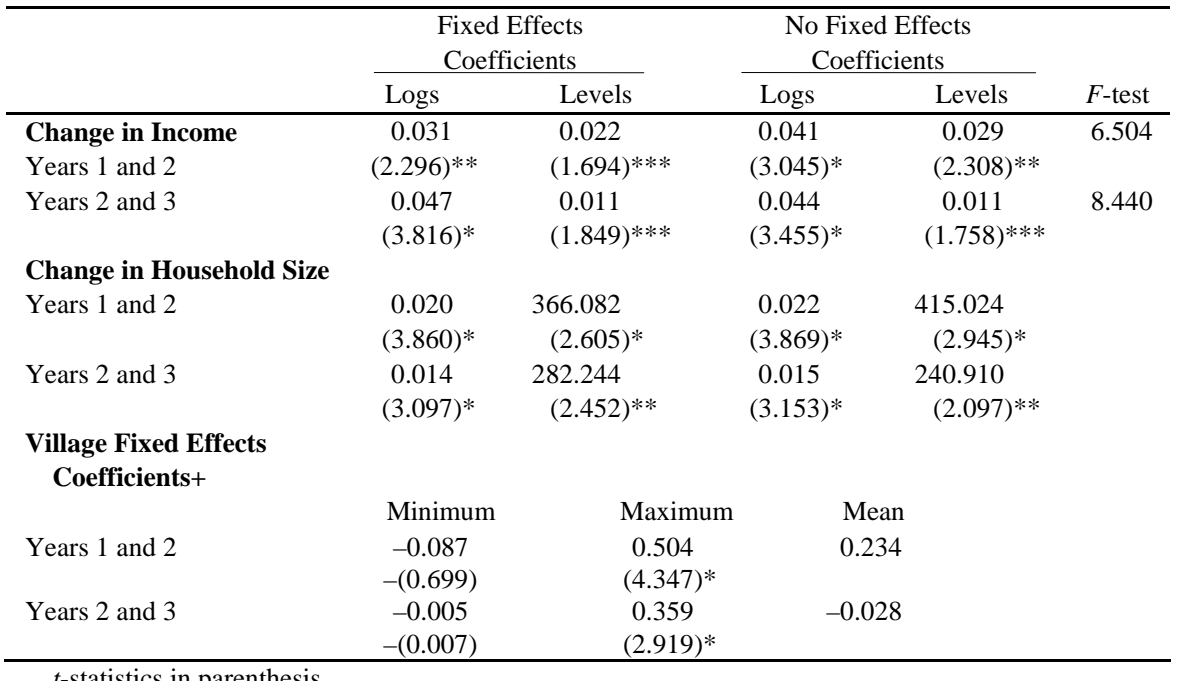

$t$-statistics in parenthesis.

* Significant at 99 percent confidence level.

** Significant at 95 percent confidence level.

*** Significant at 90 percent confidence level.

+ Using log form of the equations.

In Table 2, the exercise of Table 1 is repeated with the difference that here non-crop income instead of total income is used. The village fixed effects again do not have a strong effect on the values of own income coefficients, and most of the income coefficients are significant and positive, though small in magnitude.

The interest here is to check whether or not the data supports the risk-sharing hypothesis for different components of consumption. Next, the fixed-effects model has been tested, using changes in food consumption instead of total consumption of the household. Table 3 reports the results of this model. In this table, total income is defined as in Table 1. The dependent variable, i.e., food consumption, includes food received as gifts/wages/own production. The demographics list is the same as in previous tables. Results in this table again reject the risk-sharing hypothesis. Most of the own income coefficients are highly significant and are positive, though small in value. In this case, mean value of the village effects is also positive for both equations. These results again do not support the risk-sharing hypothesis, i.e., after controlling for the village fixed effects, the own income coefficients only change slightly in magnitude. In all of these tests, household's own income is being taken as exogenous. Since utility function used in these tests does not include the utility of the leisure term, labour income is included in total income to test the risk-sharing model. 
Table 2

Risk-sharing Within- and Across-villages Total Expenditures and Non-crop Income

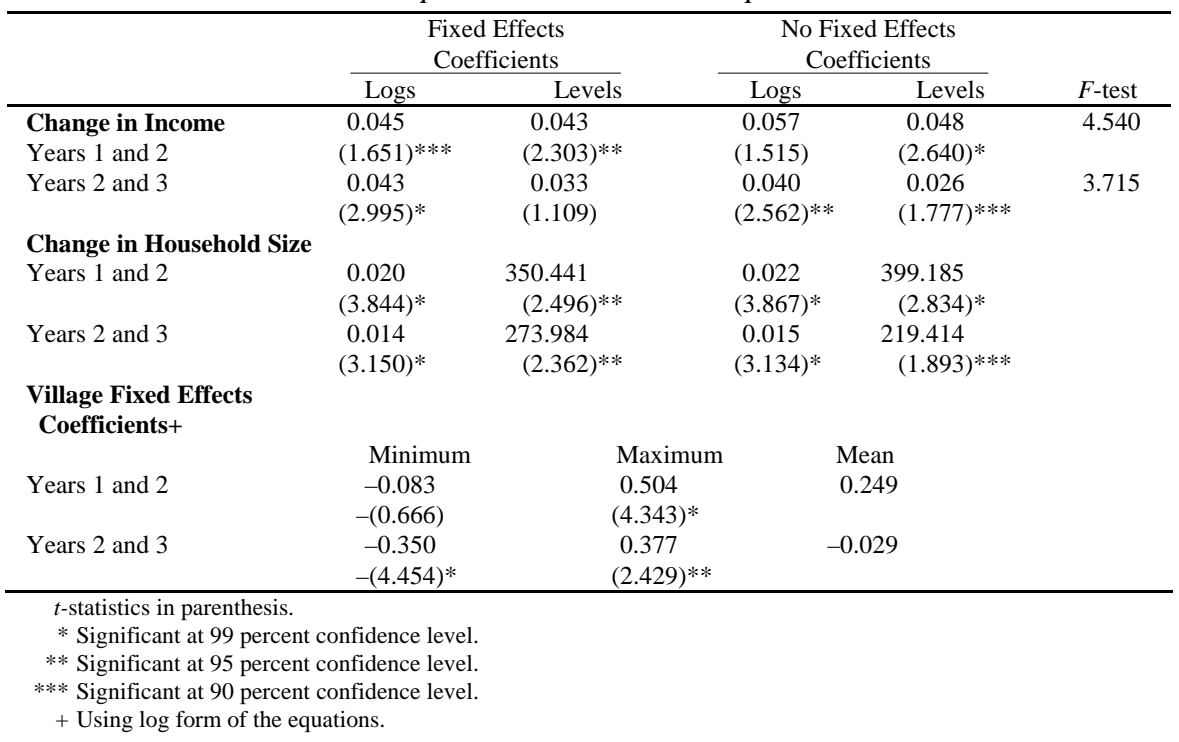

Table 3

Risk-sharing Within- and Across-villages Food Expenditures and Total Income

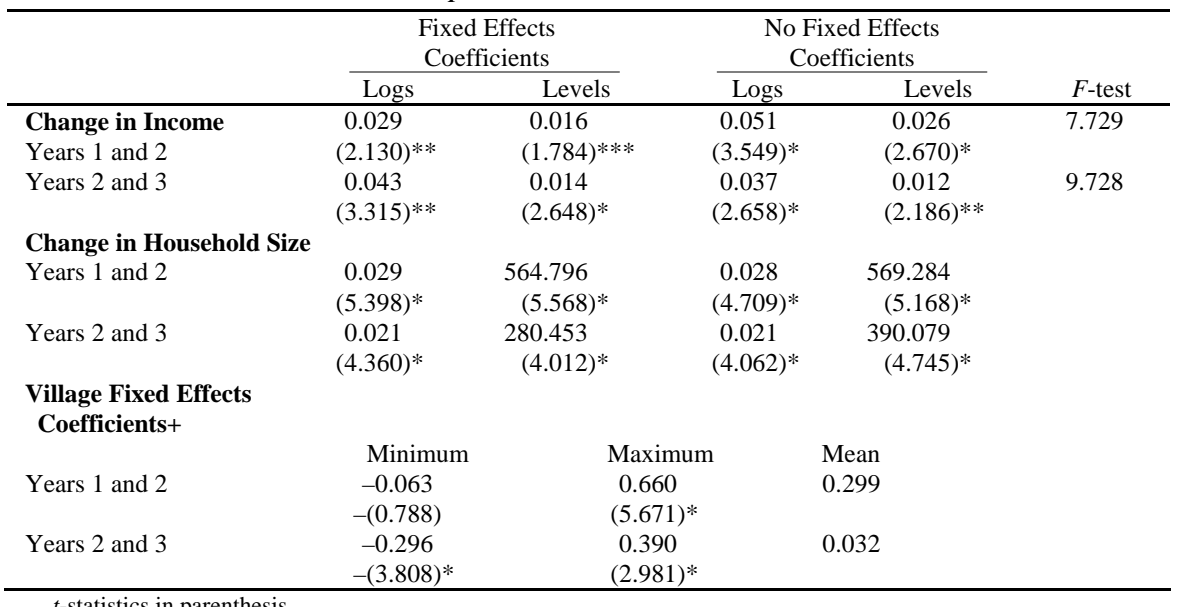

$t$-statistics in parenthesis.

* Significant at 99 percent confidence level.

** Significant at 95 percent confidence level.

*** Significant at 90 percent confidence level.

+ Using log form of the equations. 
Table 4 repeats the above exercise, with the change that here only changes in food expenditure and changes in non-crop income are used instead of changes in total income. The idea is that non-crop income is supposed to be more stable than the total income, which includes crop income. Here again, food expenditures include the food received as gifts/wages/own production. The results are similar to those in the previous table. Most of the income coefficients are highly significant and positive in both forms. This implies that if we take only changes in food expenditures against changes in non-crop income, the changes in households' own non-crop income still have positive and significant effects on the changes in consumption. Again, controlling for village fixed effects does not change the own income coefficients in magnitude.

Table 4

Risk-sharing Within- and Across-villages Food Expenditures and Non-crop Income

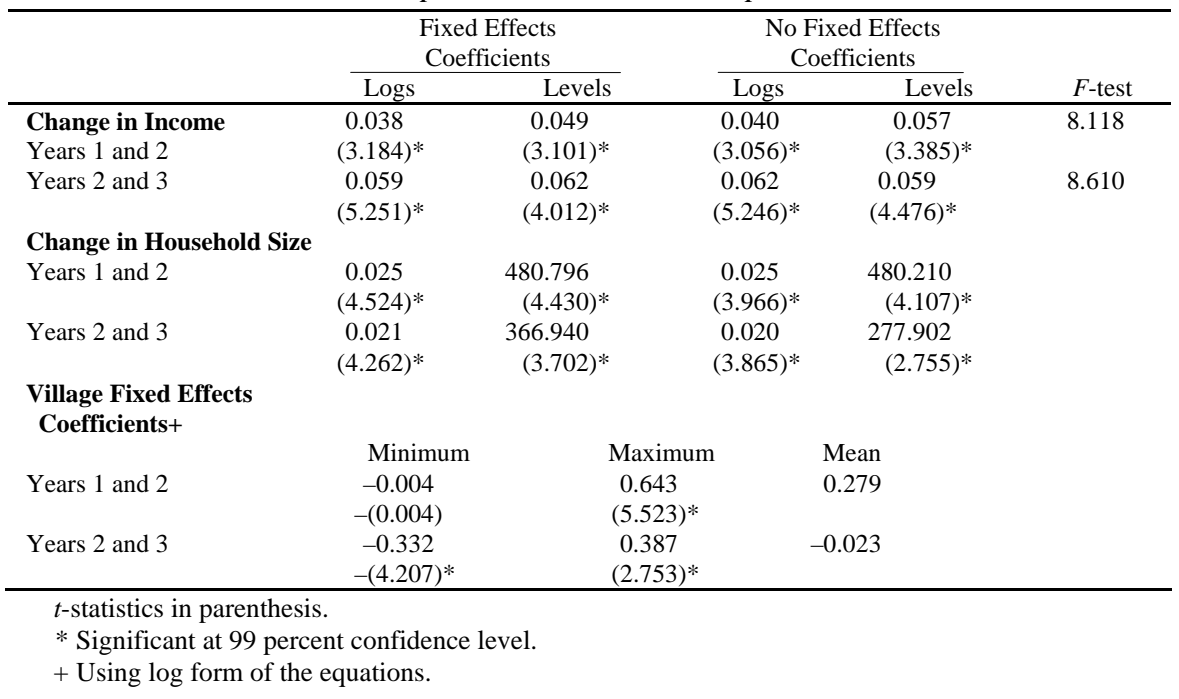

Another way to test the hypothesis of perfect risk-sharing is to use nondurable expenditures, excluding food expenditure, in the model. The examples of these expenditures are expenditures on ceremonies, functions, weddings, clothing, and entertainment. These are the type of expenditures where one expects to see a type of positive evidence of risk-sharing within villages. The results from these regression are presented in Table 5 . In this case, coefficients for the years 2 and 3 regression do reject the hypothesis of risk-sharing but they are not significant, and coefficient for the years 1 and 2 regression becomes negative after controlling for village fixed effects; so a conclusion can not be reached in this case. 
Table 5

Risk-sharing Within- and Across-villages Non-durable Expenditure (Excluding Food) and Total Income

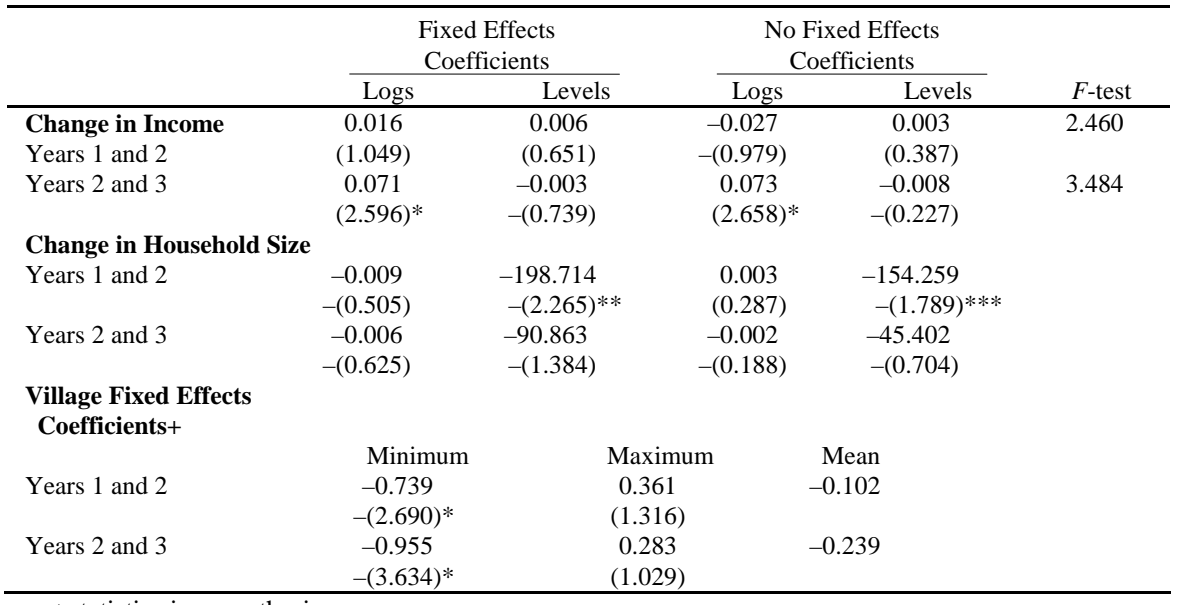

$t$-statistics in parenthesis

* Significant at 99 percent confidence level.

** Significant at 95 percent confidence level.

*** Significant at 90 percent confidence level.

+ Using log form of the equations.

In all of these tables, the $F$ statistics is included to test the risk-sharing across villages. As discussed earlier, the hypothesis of the non-equality of all components of $\tau$ vector is rejected on the basis of $F$ tests, i.e., in all cases, the null hypothesis of perfect risk-sharing across villages is rejected.

\section{IV-b Results of Risk-sharing within and across Districts}

Tables 6-9 present the results of the risk-sharing model when the risk-sharing pool is defined as a district rather than a village. For risk-sharing within districts, all households from one district have been used in the regression, including village effects for only that district. Table 6 presents the case when total income and total consumption are used. The first four rows present each district's fixed and non-fixed effects for years one and two, and the last four for years two and three. The results for District One reject the hypothesis of a risk-sharing model for both years, i.e., most of the income coefficients are significant and positive. Although these coefficients are smaller when the village fixed effects for this district are included, yet the difference is very small. In this sample, District One is the district of Faisalabad of Punjab province, which was included in the survey as a relatively prosperous rural district. For District Two, two out of four coefficients are significant (in log form of equation) and the inclusion of village fixed effects does not change the coefficients, hence 
Table 6

Risk-sharing Within- and Across-districts

Total Expenditures and Total Income

\begin{tabular}{|c|c|c|c|c|c|}
\hline \multirow[b]{2}{*}{ Change in Income } & \multicolumn{2}{|c|}{$\begin{array}{c}\text { Fixed Effects } \\
\text { Coefficients } \\
\end{array}$} & \multicolumn{2}{|c|}{$\begin{array}{c}\text { No Fixed Effects } \\
\text { Coefficients }\end{array}$} & \multirow[b]{2}{*}{$F$-test $^{\mathrm{a}}$} \\
\hline & Logs & Levels & Logs & Levels & \\
\hline Years 1 and 2 & & & & & 31.79 \\
\hline District 1 & 0.060 & 0.041 & 0.086 & 0.048 & \\
\hline 137,6 & $(1.252)$ & $(1.947)^{* * *}$ & $(1.779)^{* * *}$ & $(2.214)^{* *}$ & \\
\hline District 2 & 0.004 & 0.009 & 0.007 & 0.012 & \\
\hline 145,8 & $(0.147)$ & $(0.207)$ & $(0.026)$ & $(0.289)$ & \\
\hline District 3 & 0.123 & 0.004 & 0.114 & 0.007 & \\
\hline 238,19 & $(3.336)^{*}$ & $(0.279)$ & $(3.061)^{*}$ & $(0.479)$ & \\
\hline District 4 & 0.047 & -0.025 & 0.057 & -0.007 & \\
\hline 182,11 & (1.180) & $-(0.630)$ & (1.525) & $-(0.019)$ & \\
\hline Years 2 and 3 & & & & & 65.39 \\
\hline \multirow[t]{2}{*}{ District 1} & 0.111 & 0.012 & 0.113 & 0.011 & \\
\hline & $(2.080)^{* *}$ & (1.463) & $(2.092)^{* *}$ & (1.286) & \\
\hline \multirow[t]{2}{*}{ District 2} & 0.006 & -0.008 & 0.012 & -0.004 & \\
\hline & (0.195) & $-(0.201)$ & $(0.415)$ & $-(0.106)$ & \\
\hline \multirow[t]{2}{*}{ District 3} & 0.057 & 0.025 & 0.078 & 0.033 & \\
\hline & $(1.686)^{* * *}$ & $(1.766)^{* * *}$ & $(2.289)^{* *}$ & $(2.320)^{* *}$ & \\
\hline \multirow[t]{2}{*}{ District 4} & 0.031 & -0.029 & 0.017 & -0.036 & \\
\hline & $(0.960)$ & $-(1.209)$ & $(0.544)$ & $-(1.519)$ & \\
\hline
\end{tabular}

t-statistics in parenthesis.

* Significant at 99 percent confidence level.

** Significant at 95 percent confidence level.

*** Significant at 90 percent confidence level.

${ }^{a}$ Using $\log$ form of the equations. 
Table 7

Risk-sharing Within- and Across-districts Food Expenditures and Total Income

\begin{tabular}{|c|c|c|c|c|c|}
\hline \multirow[b]{2}{*}{ Change in Income } & \multicolumn{2}{|c|}{$\begin{array}{l}\text { Fixed Effects } \\
\text { Coefficients }\end{array}$} & \multicolumn{2}{|c|}{$\begin{array}{l}\text { No Fixed Effects } \\
\text { Coefficients }\end{array}$} & \multirow[b]{2}{*}{$F$-test $^{\mathrm{a}}$} \\
\hline & Logs & Levels & Logs & Levels & \\
\hline Years 1 and 2 & & & & & 41.66 \\
\hline District 1 & 0.068 & 0.030 & 0.102 & 0.037 & \\
\hline 137,6 & (1.313) & $(1.654)^{* * *}$ & $(1.954)^{* * *}$ & $(1.944)^{* * *}$ & \\
\hline District 2 & 0.011 & 0.056 & 0.012 & 0.051 & \\
\hline 145,8 & $(2.388)^{*}$ & $(1.708)^{* * *}$ & $(1.240)$ & (1.587) & \\
\hline District 3 & 0.075 & -0.022 & 0.069 & -0.020 & \\
\hline 238,19 & $(2.032)^{* *}$ & $-(1.766)^{* * *}$ & $(1.818)^{* * *}$ & $-(1.593)$ & \\
\hline District 4 & 0.017 & 0.038 & 0.029 & 0.011 & \\
\hline 182,11 & (1.546) & $(0.007)$ & $(1.919)^{* * *}$ & $(0.568)$ & \\
\hline Years 2 and 3 & & & & & 79.29 \\
\hline \multirow[t]{2}{*}{ District 1} & 0.076 & 0.015 & 0.084 & 0.012 & \\
\hline & $(2.212)^{* *}$ & (1.573) & (1.304) & $(1.262)$ & \\
\hline \multirow[t]{2}{*}{ District 2} & 0.026 & -0.013 & 0.023 & -0.007 & \\
\hline & $(2.186)^{* *}$ & $-(0.559)$ & $(2.811)^{*}$ & $-(0.304)$ & \\
\hline \multirow[t]{2}{*}{ District 3} & 0.062 & 0.031 & 0.064 & 0.029 & \\
\hline & $(1.910)^{* * *}$ & $(2.493)^{* *}$ & $(1.775)^{* * *}$ & $(2.214)^{* *}$ & \\
\hline \multirow[t]{2}{*}{ District 4} & 0.014 & -0.023 & 0.002 & -0.020 & \\
\hline & $(1.424)$ & $-(2.045)$ & $(0.057)$ & $-(1.607)$ & \\
\hline
\end{tabular}

$t$-statistics in parenthesis.

* Significant at 99 percent confidence level.

** Significant at 95 percent confidence level.

*** Significant at 90 percent confidence level.

${ }^{a}$ Using log form of the equations. 
Table 8

Risk-sharing Within- and Across-districts

Food Expenditures and Non-crop Income

\begin{tabular}{|c|c|c|c|c|c|}
\hline \multirow[b]{2}{*}{ Change in Income } & \multicolumn{2}{|c|}{$\begin{array}{l}\text { Fixed Effects } \\
\text { Coefficients }\end{array}$} & \multicolumn{2}{|c|}{$\begin{array}{c}\text { No Fixed Effects } \\
\text { Coefficients }\end{array}$} & \multirow[b]{2}{*}{$F$-test ${ }^{\mathrm{a}}$} \\
\hline & Logs & Levels & Logs & Levels & \\
\hline Years 1 and 2 & & & & & 44.03 \\
\hline District 1 & 0.056 & 0.076 & 0.066 & 0.081 & \\
\hline 137,6 & $(2.775)^{*}$ & $(2.056)^{* *}$ & $(1.985)^{* *}$ & $(2.105)^{* *}$ & \\
\hline District 2 & 0.032 & 0.055 & 0.044 & 0.051 & \\
\hline 145,8 & (1.234) & $(1.450)$ & $(1.710)^{* * *}$ & (1.360) & \\
\hline District 3 & 0.030 & -0.031 & -0.006 & -0.056 & \\
\hline 238,19 & $(1.550)^{*}$ & $-(1.115)$ & $-(0.286)$ & $-(1.963) * * *$ & \\
\hline District 4 & 0.024 & 0.039 & 0.029 & 0.051 & \\
\hline 182,11 & (1.366) & $(1.789)^{* * *}$ & $(2.705)^{*}$ & $(2.341)^{* *}$ & \\
\hline Years 2 and 3 & & & & & 67.98 \\
\hline \multirow[t]{2}{*}{ District 1} & 0.088 & 0.096 & 0.102 & 0.107 & \\
\hline & $(2.634)^{*}$ & $(2.233)^{* *}$ & $(2.991)^{*}$ & $(2.480)^{* *}$ & \\
\hline \multirow[t]{2}{*}{ District 2} & 0.049 & 0.039 & 0.046 & 0.032 & \\
\hline & $(2.178)^{* *}$ & $(1.241)$ & $(2.176)^{* *}$ & (1.075) & \\
\hline \multirow[t]{2}{*}{ District 3} & 0.071 & 0.095 & 0.073 & 0.105 & \\
\hline & $(4.132)^{*}$ & (1.075) & $(4.048)^{*}$ & $(5.169)^{*}$ & \\
\hline \multirow[t]{2}{*}{ District 4} & 0.016 & 0.009 & 0.012 & 0.010 & \\
\hline & $(0.841)$ & $(0.299)$ & $(0.636)$ & $(0.334)$ & \\
\hline
\end{tabular}

t-statistics in parenthesis.

* Significant at 99 percent confidence level.

** Significant at 95 percent confidence level.

*** Significant at 90 percent confidence level.

${ }^{a}$ Using log form of the equations. 
Table 9

Risk-sharing Within- and Across-districts Non-durable Expenditure (Excluding Food) and Total Income

\begin{tabular}{|c|c|c|c|c|c|}
\hline \multirow[b]{2}{*}{ Change in Income } & \multicolumn{2}{|c|}{$\begin{array}{l}\text { Fixed Effects } \\
\text { Coefficients }\end{array}$} & \multicolumn{2}{|c|}{$\begin{array}{c}\text { No Fixed Effects } \\
\text { Coefficients }\end{array}$} & \multirow[b]{2}{*}{$F$-test $^{\mathrm{a}}$} \\
\hline & Logs & Levels & Logs & Levels & \\
\hline Years 1 and 2 & & & & & 53.78 \\
\hline District 1 & -0.036 & 0.011 & -0.023 & 0.012 & \\
\hline 137,6 & $-(0.427)$ & (1.311) & $-(0.278)$ & (1.356) & \\
\hline District 2 & 0.003 & -0.046 & -0.013 & -0.039 & \\
\hline 145,8 & $(0.005)$ & $-(1.665)^{* * *}$ & $-(0.231)^{*}$ & $-(1.432)$ & \\
\hline District 3 & 0.251 & 0.026 & 0.236 & 0.028 & \\
\hline 238,19 & $(2.903)^{*}$ & $(3.130)^{*}$ & $(2.884)^{*}$ & $(3.485)^{*}$ & \\
\hline District 4 & 0.047 & -0.025 & 0.041 & -0.011 & \\
\hline 182,11 & $(0.410)$ & $-(0.807)$ & $(0.368)$ & $-(0.380)$ & \\
\hline Years 2 and 3 & & & & & 32.14 \\
\hline \multirow[t]{2}{*}{ District 1} & 0.190 & -0.002 & 0.180 & -0.002 & \\
\hline & $(2.014)^{* *}$ & $-(0.421)$ & $(1.954)^{* *}$ & $-(0.514)$ & \\
\hline \multirow[t]{2}{*}{ District 2} & -0.032 & -0.024 & -0.013 & -0.018 & \\
\hline & $-(0.498)$ & $-(0.982)$ & $-(0.203)$ & $-(0.782)$ & \\
\hline \multirow[t]{2}{*}{ District 3} & 0.068 & 0.009 & 0.138 & 0.007 & \\
\hline & $(0.825)$ & $(0.105)$ & $(1.713)^{* * *}$ & $(0.921)$ & \\
\hline \multirow[t]{2}{*}{ District 4} & 0.122 & -0.009 & 0.091 & -0.011 & \\
\hline & (1.279) & $-(0.631)$ & $(1.022)$ & $-(0.760)$ & \\
\hline
\end{tabular}

$t$-statistics in parenthesis.

* Significant at 99 percent confidence level.

** Significant at 95 percent confidence level. *** Significant at 90 percent confidence level.

${ }^{a}$ Using log form of the equations.

rejecting the hypothesis of perfect risk-sharing within the district for both years. This is the district of Attock in Punjab province. For District Three, although all four coefficients in logarithmic form are significant and positive, their value is smaller in the non-fixed effect model than in the fixed effects model for the second year's regression. The hypothesis of risk-sharing is also rejected for this district. For District Four, most of the own income coefficients are not significant. Hence no conclusion 
about the hypothesis for this district is derived. In the sample, District Three is the Badin district of Sindh province and District Four is the Dir district of the N.W.F.P.

Tables 7 to 9 report the district-level results, using different disaggregate levels of consumption or incomes. Table 7 reports the district-level results when the changes in food consumption are regressed on the changes in total income. In this table, for the fixed effects model as well as the non-fixed effects model, most of the coefficients are significant if the log form of the regression is being considered. This, again, rejects the hypothesis of the risk-sharing within districts if food consumption is the dependent variable.

Table 8 repeats the above exercise with the exception that here the changes in food consumption are regressed on the changes in non-crop income. In the fixed effects and non-fixed effects models (in log form), most of the coefficients are significant and positive, hence suggesting the rejection of risk-sharing within districts.

Table 9 represents the case when the changes in other current expenditures are regressed against the changes in total income of the households. This table suggests a mix of results, however; most of the coefficients are not significant, which leads us to reject the hypothesis of risk-sharing within-district.

For risk-sharing across districts, a slightly different approach of risk-sharing across-districts has been used as compared to the across-village analysis. For acrossdistricts, the equation of risk-sharing is regressed using the total data set without any fixed effects; this gives the residual sum of squares for the restricted model. Then the regression is repeated, controlling for districts by using a dummy for each district, hence giving the residual sum of squares for the unrestricted model. Then $F$ statistics has been calculated as defined in the previous section. These $F$ values are reported in the last columns of Tables 6 through 9. Only the log forms of the regressions are used in these $F$ tests. These $F$ tests strongly reject the evidence of risk-sharing acrossdistricts in the sample.

\section{SUMMARY AND CONCLUSION}

This study analyses the evidence of risk-sharing in the rural sector of Pakistan. The results are in contrast with Townsend (1989) and Rosenzweig (1988). Townsend finds strong evidence that the consumption of individuals in the three villages in the semi-arid tropics of India co-moves with the aggregate consumption of each village, i.e., he finds significant risk-pooling within each of his three villages. Rosenzweig, using transfer data, also finds significant risk-pooling within Indian villages. As discussed earlier, the calculation of community-wide shock is the main reason for arriving at such results. Rashid (1990), using a household survey data from Pakistan for the year 1985-86, concludes that individual consumption is not affected by individual's current income; rather, it is a function of both the average lifetime 
endowment of the individual and the aggregate community-wide shock. The main reasons for these results can be the following. First, the study uses only one-year data of farm households. Agricultural incomes generally move together in a given community in a given year, and hence may not reflect an established pattern of risksharing. Second, farm incomes constitute only 40 percent of total rural incomes, and thus the conclusion of risk-sharing within communities cannot be generalised. Third, as discussed earlier, the community-wide shock actually picked up community's fixed effects and led towards the reported results. Unlike Rashid, the results in this study indicate that the changes in the household's current income do have significant effects on the changes in the household's consumption, hence rejecting the predictions of the perfect risk-sharing model. Since panel data sets reflect established patterns of the underlying behaviour of the community, the conclusions drawn in this study-of very little or almost no risk-sharing within- and across-villages-are more reliable. The conclusions have also been confirmed by Alderman et al. (1992, 1993), and are in accord with Kotlikoff (1988), Altonji, Hayashi, and Kotlikoff (1989), and Cochrane (1991). Different possible disaggregate levels of consumption as well as income variables have been used to investigate this result. A feature that raises the importance of this study is the use of a micro panel data set on a sample of households from the rural sector of Pakistan. The risk-sharing model has also been analysed at two different levels of the economy, i.e., defining two different levels of risk-sharing pools. In the first part, it defines the risk-sharing pool as a village and tests the implications of the model within village and across-village levels. In the second part, it defines the risk-sharing pool as a district and tests the implications both within district and across-district levels. In summary, the tests reject the risksharing hypothesis more strongly in the within- and across-village analysis than in the within- and across-districts analysis. 


\section{Appendices}

\section{APPENDIX 1}

Deriving First-order Conditions for the Household Utility Function Maximisation of utility function:

$$
U_{i, j, t}=\sum P_{a, i, j, t} \theta_{a, i, j, t} \frac{C_{a, j, j, t}^{1-\gamma}}{(1-\gamma)} \quad \ldots \quad \ldots \quad \ldots \quad \ldots \quad(\mathrm{A}-1.1)
$$

Subject to household budget constraint:

$$
C_{i, j, t}=\sum P_{a, i, j, t} C_{a, i, j, t}
$$

For any given age group in a given household, the optimal value of the consumption can be derived by solving for $C_{a, i, j, t}$ from budget constraint:

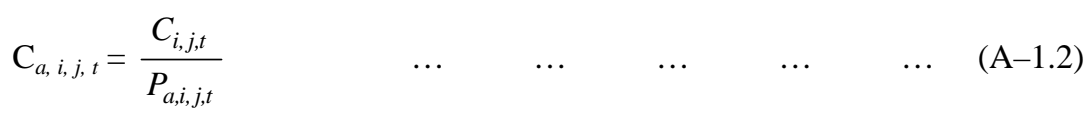

substituting this value back in the utility function:

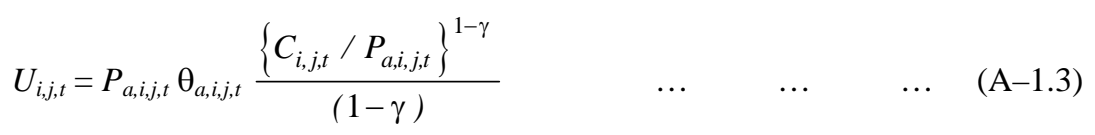

rearranging the terms and summing over all age groups in a household, we get the following:

$U_{i, j, t}=\left\{\sum_{a=0}^{D} P_{a, i, j, t} \theta_{a, i, j, t}^{1 / \gamma}\right\}^{\gamma} \frac{C_{i, j, t}^{1-\gamma}}{(1-\gamma)} \quad \ldots \quad \ldots \quad \ldots \quad \ldots \quad(\mathrm{A}-1.4)$

which is the expression in (3). 


\section{APPENDIX 2}

Deriving First-order Conditions for the Risk-sharing Pool’s Utility Function Given the total risk-sharing pool's utility function:

$$
\begin{array}{llllll}
W_{j, t}=\sum_{i=1}^{N_{i}} \delta_{i, j,} H_{i, j, t} & \ldots & \ldots & \ldots & \ldots & (\mathrm{A}-2.1)
\end{array}
$$

Substituting the value of $H_{i, j, t}$ from (4) into the utility function:

$$
W_{j, t}=\sum_{i=1}^{N_{j}} \delta_{i, j,}\left\{E_{t} \sum_{s=t}^{\infty} U_{i, j, s}\left(\frac{1}{1+\rho}\right)^{s-t}\right\} \quad \ldots \quad \ldots \quad(\mathrm{A}-2.2)
$$

Substituting the household utility function, i.e., $U_{i, j, t}$ from (3) into (A-2.2):

$$
W_{j, t}=\sum_{i=1}^{N_{j}} \delta_{i, j,}\left\{E_{t} \sum_{s=t}^{\infty} B_{i, j, t} \frac{C_{i, j, t}^{1-\gamma}}{(1-\gamma)}\right\} \quad \ldots \quad \ldots \ldots
$$

Our problem is to maximise the total risk-pool's utility function (A-2.3) subject to the pool's given resources for any given period, i.e., $s=t$, total budget constraint is given as:

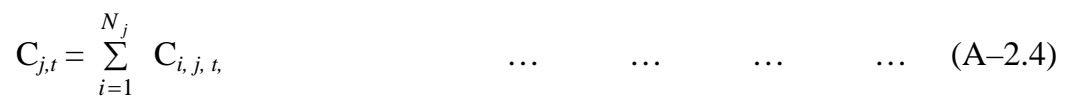

Maximising (A-2.3) subject to (A-2.4) at one point of time $s=t$, the static first-order condition (by setting the langrange) is derived as follows, taking $C_{j, t}$ as given,

$$
L=\delta_{i, j} E_{t} \sum_{s=1}^{\infty} B_{i, j, t} \frac{C_{i, j, t}^{1-\gamma}}{(1-\gamma)}+\lambda_{j, t}\left\{C_{j, t}-\sum C_{i, j, t}\right\}
$$

taking the first derivative with respect to $C_{i, j, t}$ we have the first-order condition as given in (7):

$$
\delta_{i, j} B_{i, j, t} \frac{C_{i, j, t}^{1-\gamma}}{(1-\gamma)}-\lambda_{j, t}=0 \quad \ldots \quad \ldots \quad \ldots \quad \ldots \quad \ldots \quad(\mathrm{A}-2.5)
$$




\section{REFERENCES}

Adams, Richard H. Jr. (1992) The Effects of Internal and International Migration and Remittances on Income Distribution in Rural Pakistan. Washington, D. C.: International Food Policy Research Institute (IFPRI Report).

Alderman, Harold, and Christina H. Paxson (1992) Do the Poor Insure? A Synthesis of the Literature on Risk and Consumption in Developing Countries. Washington, D. C.: The World Bank (WB Working Paper).

Alderman, Harold, and Marito Garcia (1993) Poverty, Household Food Security and Nutrition in Rural Pakistan: A Longitudinal Study. Washington, D. C.: International Food Policy Research Institute (IFPRI Report).

Altonji, Joseph G., Fumio Hayashi, and Laurence J. Kotlikoff (1989) Is the Extended Family Altruistically Linked? Direct Tests Using Micro Data. Cambridge: National Bureau of Economic Research (NBER Working Paper No. 3046).

Andrew, Abel B., and Laurence J. Kotlikoff (1988) Does the Consumption of Different Age Groups Move Together? A New Non-parametric Test of Intergenerational Altruism. Cambridge, Massachusetts: National Bureau of Economic Research (NBER Working Paper No 2490).

Browning, Martin, Angus Deaton, and Margaret Irish (1985) A Profitable Approach to Labour Supply and Commodity Demand over the Life-cycle. Econometrica 53:3 503-43.

Cochrane, John (1991) A Simple Test of Consumption Insurance. Journal of Political Economy 99:5 957-76.

Deaton, Angus (1989) Saving in Developing Countries: Theory and Review. Princeton, New Jersey: Princeton University, Woodrow Wilson School (Discussion Paper No. 144).

Gillani, Fizza S. (1994) Evidence of Risk Sharing and the Role of Transfers and Loans: The Case of Rural Pakistan. Boston, Massachusetts: Department of Economics, Boston University (Ph. D. dissertation).

Kotlikoff, Laurence J., and Ariel Pakes (1988) Looking for the News in the Noise: Additional Stochastic Implications of Optimal Consumption Choice. Annales d'Economie et de Statistique 9.

Kotlikoff, Laurence J., and Avia Spivak (1981) The Family as an Incomplete Annuities Market. Journal of Political Economy 89:2 372-91.

Mace Barbara (1991) Full Insurance in the Presence of Aggregate Uncertainty. Journal of Political Economy 99:5 928-56.

Pakistan, Government of (1986-87, 1990-91) Pakistan Economic Survey. Islamabad: Statistical Division.

Paxson, Christina H. (1988) Household Savings in Thailand: Responses to Income Shocks. Princeton, New Jersey: Princeton University, Woodrow Wilson School (Discussion Paper No. 137). 
Rashid, Mansoora (1990) Rural Consumption, Risk and Insurance: The Evidence from Rural Pakistan. Chicago, ILL.: Department of Economics, University of Chicago. (Mimeograph.)

Rosenzweig, Mark (1988) Risk, Implicit Contracts and the Family in Rural Areas of Low-Income Countries. The Economic Journal 98:6 1148-70.

Rosenzweig, Mark, and Oded Stark (1989) Consumption Smoothing, Migration, and Marriage: Evidence from Rural India. Journal of Political Economy 97:4 905-26.

Townsend, Robert M. (1989) Risk and Insurance in Village India. Chicago, ILL.: Department of Economics, University of Chicago. (Manuscript.)

Wilson, Robert B. (1968) The Theory of Syndicates. Econometrica 36:1 119-32. 